\title{
Editorial 2020-1 - O Ensino de Bioquímica em meio à pandemia de COVID-19
}

A Revista de Ensino de Bioquímica possui periodicidade semestral e, após a publicação do número 2 de 2019, o mundo foi acometido pela pandemia do vírus Sars-CoV-2. Se as dificuldades para o Ensino no Brasil já são enormes, somaram-se agora todos os transtornos advindos da disseminação desse vírus e, com eles, os diversos dramas pessoais e coletivos que estamos testemunhando. Em meio a esse novo cenário, devo agradecimentos especiais ao conjunto de colaboradores da Revista de Ensino de Bioquímica que manteve as avaliações dos trabalhos submetidos, permitindo a publicação desta edição. Agradeço a esses excepcionais profissionais que compreendem a importância da missão da nossa revista para o ensino da Bioquímica em nosso país e nos demais aos quais ela consegue chegar. Profissionais que realizaram o trabalho de avaliação dos artigos submetidos, em suas casas, dividindo seu tempo com os cuidados às suas famílias. Alguns, imagino eu, com parentes internados com a COVID 19 (eu mesmo, passei por essa situação). E se algum dos avaliadores, autores ou leitores dessa revista tiveram alguma perda, familiar ou não, para o coronavírus, deixo aqui meus sinceros sentimentos e profundos pêsames.

Mesmo com todas essas dificuldades, tivemos um número expressivo de submissões de trabalhos à revista e o número 1 de 2020 apresenta oito artigos publicados. Na seção REB na Escola temos três trabalhos: um sobre a produção de vídeos no ensino de Bioquímica e Química Orgânica; outro sobre o uso de experimento de microbiologia para aula investigativa do ensino médio, e um terceiro sobre o ensino de Bioquímica e Microbiologia por meio de aulas práticas interdisciplinares. Na seção Pesquisa em Ensino há dois trabalhos: O ensino de Biologia Celular e Molecular na formação inicial docente a partir do método Team-based-learning - que explora a metodologia de ensino baseado em grupos, e Panorama dos trabalhos de educação apresentados nas reuniões anuais da Sociedade Brasileira de Bioquímica e Biologia Molecular entre 1993 e 2019. Em Imagem Pública e Divulgação Científica vocês encontrarão um levantamento dos cursos de bacharelado em Bioquímica no Brasil. Por fim, em Inovações Educacionais há dois artigos: um em que é apresentada uma proposta para o trabalho da cariotipagem em sala de aula e, outro, com o emprego da metodologia da sala de aula invertida para o processo de ensino-aprendizagem da Bioquímica.

Essa edição da REB ainda traz um elemento marcante de sua história: o Regimento da Revista. Nosso Conselho Editorial elaborou o Regimento e a Diretoria da Sociedade Brasileira 
de Bioquímica e Biologia Molecular (SBBQ) o aprovou. Esse documento pode ser verificado nas páginas que se seguem e determina a organização estrutural da Revista e suas competências.

Cordiais abraços,

André Bianco.

Editor Chefe

\section{REGIMENTO DA REVISTA DE ENSINO DE BIOQUÍMICA}

\section{ORGANOGRAMA}

O corpo editorial da Revista de Ensino de Bioquímica deve ser composto por um editor sênior, um editor chefe, quatro editores adjuntos e revisores, todos pesquisadores e docentes, com notório saber e produtividade comprovada na área do Ensino de Bioquímica.

Os editores sênior, chefe e adjuntos compõem o Conselho Editorial da revista.

\section{COMPETÊNCIAS}

Art. 1 Ao conselho editorial da Revista de Ensino de Bioquímica compete:

I. Coordenar o processo de escolha e aprovar o nome do editor chefe e dos editores adjuntos para cada mandato;

II. Zelar pelo cumprimento das atribuições dos editores e substituí-los caso suas atribuições não estejam sendo cumpridas adequadamente;

III. Deliberar sobre decisões relativas a políticas editoriais da Revista de Ensino de Bioquímica, tais como: mudanças de missão, escopo e foco, público-alvo, identidade visual, processo editorial e periodicidade;

IV. Avaliar criticamente os trabalhos enviados para a revista;

V. Dar o parecer final a trabalhos que tenham tido avaliação indefinida;

VI. Quando denunciados, investigar casos de plágio em artigos submetidos à revista;

VII. Buscar novas parcerias que contribuam para a divulgação da revista e o aumento do número de trabalhos submetidos a ela;

VIII. Participar de eventos científicos para divulgação da revista;

IX. Discutir e aprovar as alterações de regulamento.

$\S 1^{\circ} \mathrm{O}$ Editor chefe coordena o processo editorial buscando promover o desenvolvimento dos trabalhos submetidos à Revista de Ensino de Bioquímica, de seus autores e revisores. A escolha do editor chefe deverá considerar fatores como: liderança científica, reconhecimento 
da comunidade, histórico de atuação como revisor e autor e seu projeto de trabalho para o periódico.

$\S 2^{\circ} \mathrm{O}$ mandato do editor chefe será de dois anos, sendo permitidas reconduções.

$\S 3^{\circ} \mathrm{A}$ eleição do editor chefe será feita por voto aberto. O editor será eleito se obtiver a maioria dos votos do Conselho Editorial (quatro votos).

$\S 4^{\circ}$ São elegíveis para o cargo de editor chefe os editores adjuntos.

Art. 2 Ao editor chefe da Revista de Ensino de Bioquímica compete:

I. Coordenar a equipe envolvida com o periódico, incluindo editores adjuntos, revisores e funcionários;

II. Revisar a admissão de artigos submetidos ao periódico, a ser realizada diretamente ou solicitada a um editor adjunto;

III. Recomendar a inclusão e substituição de membros do Conselho Editorial;

IV. Selecionar, avaliar e substituir consultores ad hoc;

V. Indicar revisores para os artigos submetidos à publicação;

VI. Recomendar alterações em conteúdo de artigos submetidos, embora possa eventualmente delegar essa responsabilidade a um editor adjunto ou revisor;

VII. Informar ao autor correspondente a decisão editorial ao final do processo de avaliação, e

VIII. Decidir sobre a aprovação ou a rejeição de artigos.

$\S 5^{\circ}$ Os editores adjuntos assumem o cargo na Revista de Ensino de Bioquímica a convite do seu corpo editorial. O mesmo corpo editorial deve julgar o desempenho dos seus editores adjuntos e decidir pela permanência dos mesmos no cargo.

$\S 6^{\circ} \mathrm{O}$ processo de escolha dos editores adjuntos deve considerar fatores como: reconhecimento da comunidade e histórico de atuação como revisores e autores.

$\S 7^{\circ} \mathrm{O}$ mandato dos editores adjuntos é de dois anos, sendo permitidas reconduções.

$\S 8^{\circ} \mathrm{Em}$ caso de necessidade e a critério do editor chefe, a Revista de Ensino de Bioquímica, poderá ter consultores ad hoc, sem vínculos com seções específicas do periódico, em função do volume de trabalhos submetidos e dos campos de especialização desses editores.

Art. 3 Aos editores adjuntos da Revista de Ensino de Bioquímica competem:

I. Assessorar o editor chefe na identificação de consultores ad-hoc para avaliação de trabalhos submetidos;

II. Assessorar o editor chefe na avaliação dos aspectos objetivos do processo de avaliação de manuscritos submetidos ao periódico, e

III. Assessorar o editor chefe na decisão editorial sobre a publicação. 
$\S 9^{\circ}$ Os revisores serão requeridos pelo editor chefe para realizarem serviços de editoração de trabalhos submetidos à Revista de Ensino de Bioquímica. Essa tarefa ad hoc pode ser repetida, a depender do interesse do editor convidado e do desempenho do mesmo em avaliações anteriores.

$\S 10^{\circ} \mathrm{O}$ Corpo de Revisores da Revista de Ensino de Bioquímica é um colegiado multiinstitucional, integrado por especialistas plenos de amplo reconhecimento na comunidade acadêmica nacional e internacional, distribuídos em termos tanto de seus campos científicos de especialidade, quanto geográficos, abrangendo regiões distintas do Brasil e de outros países e a mais ampla gama de campos científicos na área.

$\S 11^{\circ} \mathrm{O}$ mandato dos participantes do Corpo Editorial Científico é de dois anos, sendo permitidas reconduções.

$\S 12^{\circ} \mathrm{A}$ quantidade de membros do Corpo de Revisores é definida pelo editor chefe por ocasião do início de seu mandato e decorre das necessidades do periódico.

Art. 4 Aos revisores competem:

I. Revisão de admissão dos artigos submetidos à publicação;

II. Manter sigilo sobre o conteúdo dos artigos submetidos à publicação, e

III. Tomar decisões relativas aos aspectos científicos do processo editorial do periódico, sempre que solicitados por um dos editores.

Bayardo Baptista Torres André Amaral G. Bianco

Editor Sênior $\quad$ Editor Chefe

Eduardo Galembeck Vera Maria Treis Trindade Gabriel Gerber Hornink

Editor Adjunto Editora Adjunta $\quad$ Editor Adjunto 